\author{
Sandra Geelhoed \\ University of Applied Sciences \\ Hayley Trowbridge \\ People's Voice Media
Sarah Henderson
People's Voice Media
Lauren Wallace-Thompson
People's Voice Media

\title{
CHANGING THE STORY: AN ALTERNATIVE APPROACH TO SYSTEM CHANGE IN PUBLIC SERVICE INNOVATION
}

DOI: $10.2478 /$ ppsr-2021-0012

\begin{abstract}
Author
Dr. Sandra Geelhoed is lecturer, researcher specialized in social and cultural theory, social change, social imaginaries, collective memory and community development. She lectures at the Utrecht School of Social Work, Master Community Development. Sandra was involved as a researcher in many international projects, such as Horizon 2020 research on social innovation (InnoSI) and on cocreation (CoSIE). At the Research Centre for Social Innovation, she works on a major research project about narratives and policymaking in the Netherlands. She works as a storyteller and artist with children and adults on collective imagination and community art.
\end{abstract}

ORCID no. 0000-0002-8823-8157

e-mail: sandra.geelhoed@hu.nl

Hayley is an experienced facilitator, project manager and researcher within the fields of social innovation, social justice, arts, heritage \& culture, and education. Hayley has worked with communities across the UK and Europe to explore, learn and create change. She specialises in working with people to dismantle hierarchies and find more equitable ways of working, often with the use of creative technologies entwined. Hayley is the CEO of People's Voice Media.

ORCID no. 0000-0002-6528-3190

Sarah's background is a mix of PR, marketing, copywriting and research. The experience garnered from her 12-year career so far, has furnished her with great expertise in writing and research, as well as dissemination and communications in both the digital and traditional arenas. She is a specialist in analysing and packaging information for different audiences and being able to put herself in her reader's shoes in order to write specifically for them.Sarah is a project manager with People's Voice Media focusing on social impact.

ORCID no. 0000-0002-9363-7785

Lauren is a freelance writer and researcher with specialisms in education and third sector work. As well as researching and writing publications aimed at young people and parents, she has developed a particular expertise in co-production and Community Reporting, curating the stories of people with lived experience into reports and articles to influence change-makers. Lauren is a Freelance Associate at People's Voice Media.

ORCID no. 0000-0003-2561-460X 


\begin{abstract}
Storytelling is a powerful instrument for system change. Telling stories of lived experience, listening to them, and sharing them contributes to a culture of trust based on dignity, mutual respect and shared values. In this paper we draw attention to public service innovation and co-creation with the people the service is meant for. In the past years, public service innovation was resultand output driven, targeting technological and managerial innovation. Stories of service users revealed the unintended negative consequences of such innovation policies and opened new perspectives for conversations of change based on shared values leading to innovations based on human development and dignity.
\end{abstract}

Keywords: storytelling, system change, dignity, narratives, action research, user voice, social innovation, service innovation, public services, personalization, human development, culture of trust, cocreation

\title{
Introduction
}

In this article we will show how storytelling as an alternative approach contributes to a process of system change and innovation of public services. We argue that listening to stories and making them visible, contributes to 1) opportunities for seeing issues from different perspectives and avoiding unintended negative outcomes of (public) social service delivery for people who depend upon them and 2) opening up conversations for system change and the redesign of public services with all actors, including citizens for whom the service was intended.

In section 1, we will explain how Community Reporting was used within the framework of the CoSIE as an instrument to engage collective sensemaking and Participatory Action Research within a larger experimental research and action project about innovation of social services through co-creation practices.

In section 2, we will show how current public service design based on purpose-driven and instrumental rationality (Weber,1979) sustained by digital technologies, lead to - often unintentionally-added bureaucracy and the dehumanization of services, shown by de-personalization and othering of people for whom the service was designed to support in the first place.

In section 3, we address how stories, by connecting people at an empathic level and sharing personal experiences, encourage changes of mindset and behavior. Actors in different roles and positions develop common awareness on the essence of public service, its purpose and values, namely in supporting citizens in meaningful ways. Narratives in this instance are being used as instruments for service innovation and contribute to identification and acknowledgement of cracks in the system that produce social injustice instead of reducing it.

In section 4, we will apply Community Reporting as a storytelling technique within CoSIE in a broader perspective and relate our findings to the wider calling for paradigm shift within public governance as introduced by Rosanvallon $(2015,2020)$ and Wieviorka $(2020)$. Storytelling invites all actors to think and reflect together, offering possibilities for reframing service innovation and thus introduce storytelling as a narrative intervention within public services (Tesselaar, 2018), and a tool through which change can happen here and now. 


\section{Methodology}

Broadly based on the Cynefin decision-making framework for complex environments (Snowden and Boone, 2007), Community Reporting has been applied in the CoSIE Horizon 2020 project as a tool for supporting co-creation within innovation process of public services across Europe. From probation services through to the health sector, Community Reporting has supported services to have better insight into the worlds of the citizens they are supporting - providing them the space to set the agenda about what matters to them, open dialogue between different actors and perspectives and enable reflection from both people accessing services and the people working in them to support on-going learning and service development.

Within the CoSIE project scheme, over 250 stories of lived experiences of people who access services and public servants of different types of public services ${ }^{1}$ were collected, curated and analyzed. The present article is based on this data set and gives insight in the need for fundamental system innovation based on a paradigm shift from instrumental rationality to value rationality. Furthermore, we draw on observations in several professional networks in the Netherlands (Narrative Accountability Network, DiVoSA network on Responsive Civil Servants) and several projects run by the People's Voice Media and Community Reporters Movement.

\section{Innovative social science research in CoSIE}

Community Reporting emerged in 2007 as a digital story telling instrument to express voices of people who are not heard. It is born from community action and evolved to a useful and innovative tool in interpretative and participatory action research schemes. Thus, throughout the years, Community Reporting developed across Europe as a mixed methodological approach both based on community development and action on the one hand and research in and about communities on the other hand.

Community Reporting through the organization of People's Voice Media contributed in participatory (action) research, co-producing policy, service development and citizen engagement in decision-making and governance processes. Use of storytelling and Arts Based Research Methods (Leavy, 2007; Van Heijst et al. (2019); Geelhoed, 2019, Grieder, 2013) also show that we can speak of a "narrative turn" in the social sciences (Jackson, 2015). In fact, academic knowledge and practical (professional) knowledge are combined with experiential knowledge, incorporating stories of the heart into the study of social realities.

As Glasby (2011) and Durose et al (2013) have suggested, lived experience storytelling-such as Community Reporting-highlights how lived experience and knowledge-based practice can be used in the settings listed above and contribute to deeper and more accurate information about people's lives. Storytelling in this realm, as Durose et al (2013) argues, allows for the representation of "different voices and experiences in an accessible way". Knowledge production and sharing becomes a practice for all and not exclusively for researchers or intellectuals.

1 CoSIE consortium is composed of academic partners and professional organizations and social services in Estonia, Finland, Greece, Hungary, Italy, the Netherlands, Poland, Spain and the UK. For more information. 
This human approach to doing research was one of the basic purposes of CoSIE project, integrating practical innovation with learning strategies both for citizens, professionals, and researchers. The telling of and listening to stories through Community Reporting and peer-to-peer dialogue techniques create the possibility to share earnest and personal stories. Using audiovisual media and art-based interventions ensure that the information is transmitted through readable text. Audiovisual techniques involve all senses in understanding and interpreting the story (Geelhoed, 2019).

Within the CoSIE project, we used peer-to-peer dialogue interview techniques and collective sense-making activities based broadly on discourse analysis (Brown and Yule, 1983) and notions of grounded theory (Glaser and Strauss, 1967; Tummers and Karsten, 2012). Affiliation with interpretative and sensemaking traditions in qualitative research was combined with emancipatory and critical research tradition that was based on action research. In fact, Community Reporting was used to analyze actions and behavior and engage action, thus exploring ways for positive change for both people who access services, professionals and the public services involved.

This mixed methodology has provided a framework through which divergent and varied lived experiences of public services - through both the lens of professionals and citizens - can be amassed and synthesized into a set of learnings and findings. This dataset underpins the findings and arguments of this article.

\section{The unintended consequences of instrumental rationality in public ser- vices}

The CoSIE project was developed to propose innovation of public services based on co-creation with the citizens for whom the service was meant. In fact, this is a value-based experimental approach to innovation and asks of all actors involved to listen, not to judge and attribute equal importance to perspectives of all. It positions itself against the regular perception of (smart) innovation that is related to technological applications and data driven solutions to improve service delivery. CoSIE is in line with the findings of the Smart Urban Intermediaries project (Van Hulst et al. 2019; 2021) that focuses on innovation and development of cities, neighborhoods, services based on citizen's initiatives, valuing "smart people", their stories and actions. It relates to the idea that innovation is not about best practices only but also about best persons (Van den Brink et al., 2012), able to connect people and, by doing so, make needed community and common projects happen. This perception of innovation involves a bottom-up approach, following needs and energies of people at a given place and period of time. It also shows the importance of evolving, growing, and building together, tackling the issues at stake when they occur and using new technologies when appropriate or needed to improve people's quality of life.

The very essence of the public cause, and therefore of public services, is based on human values and meant to organize solidarity, inclusion, social justice, and equality for all citizens, rich or poor, young or old, established or an outsider or newcomer. It comes down to the idea that political representatives and public servants are at service of the community and are accountable to them. This notion of public value was at the heart of the development of national welfare states in the aftermath of World War II. It was the guiding rationality for the setting up of a care system for citizens within modern national states 
(De Swaan, 1988). This collective arrangement implied a new working area, bureaucracy to organize it and curation by the state.

However, this way of looking at responsibility of the state and human progress in terms of social equality and solidarity has become under pressure. In fact, the western idea of progress has been accompanied by a growing importance given to instrumental rationality (Zweckrational) over value rationality (Wertrational). ${ }^{2}$ Flyvbjerg (2004) calls this "the Rationalist Turn, meaning the narrowing of modern society's notion of rationality to a predominantly instrumental one" (Flyvbjerg, 2004:53). This specific idea of progress and modernization has led to technological innovation and produced economic and financial growth, which has been profitable and was seen as the best way for future development. In fact, due to (economic) globalization processes, this national welfare system was difficult to maintain.

Gradually, value rationality, proper to political and social actions, slipped to the background within public institutions guided by liberal views based on minimal state interference. Instrumental rationality based on measurable purpose, efficiency, cost and benefit analysis gradually became the way to go in the political sphere and for how the state and local authorities would act. During the 1980s and 1990s, state-owned companies were privatized, such as banks, postal services, or public transport. The state- and governmental logics became gradually dominated by instrumental rationality out of technological and economic spheres (Fox, 2017).

This development is also visible in the use of language in politics and policy making. Nicolina Montesano Montessori $(2016,2019)$ made a critical analysis of policy discourses. She stated that using terms such as human capital to speak about EU-citizens shows depersonalization and instrumentalization of the citizen to the functioning of system empowered by capital. On local levels, citizens who claim rightful financial support from public services would not be called citizens but beneficiaries or even service users, a term directly borrowed from the ICT sector. Public servants would call the citizens they assist clients or customers, which implies a relationship based on financial or economic transactions. Public institutions who were responsible to realize public services or realize social assistance or social care were obliged to reply to "open calls for proposals" on how to realize public services, giving a detailed project plan with a budget, showing provisional cost and benefit analysis. In fact, as a Dutch public servant would underline already in 2015: "local authorities operate as social investors. We do a call for tender for the realization of social policy plans" (interview, 2015). Organizations can offer proposals. If they win the bid, local authorities have a controlling role in asking for proofs of accountability and social return on investment. The very term of accountability asks for measurable proof. These terms show that local and national authorities organized themselves like businesses (Geelhoed, 2017).

In-line with this, a 2020 policy briefing based on data sets from Community Reporter Movement (Davies et al., 2020) of over 350 lived experience stories of citizens across Europe found that "process has replaced common sense, and protocol had replaced humanity" within services. The process referenced is borrowed from the processing and splitting up of tasks proper to tech processes. The authors suggest that this was caused by three

2 See Max Weber's classic study about Economy and Society, in which he outlines a classification of types of action, Zweckrational (instrumental rationality) and Wertrational (value rationality). We draw on the English Translation of Economy and Society by the University of Berkeley Press, 1978. 
intrinsically linked notions: bureaucracy, depersonalization, and othering (Davies et al., 2020). These three characteristics of how services would operate create a void between service and citizen. In fact, this barren process ultimately leads to "decision-making without empathy" based on instruments and evaluation tools rather than on human needs and human dignity. In the end, this way of working, although based on rational approach, tends to be ineffective. These conclusions based on the analysis of a dataset based on stories of lived experience show that public services have drifted away from their essential value, organize solidarity with those who need support to guarantee existence.

This is not to suggest that good pockets of practice and work do not exist in public services or that good public servants or services do not exist. It is rather to say that, overall, there has been an unforeseen consequence of years of instrumental thinking and rational choices borrowed from business, consultancy, and technology. This trend shows that humanity and relationships were valued less than the managerial structures that govern the services.

Hereafter we will highlight through the stories told in the CoSIE-project the negative impact of bureaucracy, depersonalization and othering on public services and why system change, at a fundamental level, is needed and secondly, demonstrate how storytelling as value- based practice can be one element to support system change and bringing back value rationality in public services and moreover in the political sphere.

\section{Bureaucracy and the dehumanization of public services}

Loss of personal connection. In Valencia, the CoSIE project proposed to co-create a business development and entrepreneur hub with and for unemployed people. To develop this new type of service, stories were gathered from people who were currently unemployed to better understand their needs and how current provision was working for them.

One of the people involved in this stated that "there is a lot of information online that doesn't feel helpful". She is "stuck at the moment due to bureaucracy". She felt that current services "lack empathy or connection" with the people who are contacting them. The result for persons like her is the feeling that the dream of running a successful enterprise may be unachievable. This quote shows that people do not feel encouraged in realizing the project they have in mind. They lose not only confidence in the service, but also self-confidence.

Anonymity. Bureaucracy in public services takes on several forms. This case stresses the problem of anonymous online administrative processes that hinder the effective workings of service. Although accessibility was one of the European goals of national states of e-governance and internet in public services, no reciprocal interpersonal contact was established, which left the service inefficient.

Risky benefits. The pilot in the Houten municipality in the Netherlands focused on the matching between the long-term unemployed persons and available jobs. At the start of the CoSIE-project, many jobs were available in the municipality. However, long-term unemployed persons, receiving social assistance benefits, did not find their way back to paid work. Community Reporting stories revealed a "broken" benefits and jobseeker system. The stories show that the unemployed persons were scared, confused and angry. They ended up in unsuitable jobs or even in debt because of the system organization. One individual describes that she was employed for a limited number of hours and that her scarce 
income was supplemented by the state, until the level of minimum allowance was reached. These benefits were due to stop when she received another job and higher income. Eventually, she was without enough income to run her car-which was essential to the job she had found. This pushed her to move to a more unsuitable job closer to home. This was unfortunate as the job she was in had been able to offer more hours if she could have stayed and waited for six months. This person describes the legislation as "discouraging and counterproductive," and the system itself as "a necessary evil" which they felt offered them no support. In this example, it is shown how the social services are dealing with indicators designed behind a desk and based on received income only. The experience of this person, having extra expenses to get to work, are not taken into account and leaves her with less income than while receiving social benefits.

Newcomers in Houten are often long-term unemployed people. Integration in Dutch society through work is highly promoted. However, within the same dataset, a group of Eritrean women point to the system and its bureaucracy as being confusing. One woman spoke of her experience when she was 22 . Having received refugee status, she was given a house to live in as well as benefits. However, a year later she received a letter from the tax office demanding her to repay $€ 3,000$, an amount of money she did not have. She eventually managed to get help from a local welfare organisation but this took a lot of time and effort.

She blames the lack of information available at the start of the process: "You find out because it happens to you, but you really should have this information in advance." Another woman in the group suggested that the language barrier is an issue as the information that is available online is only in Dutch. The language barrier also makes fixing the problem a slower process. Another woman added that they wait in fear for what might happen with their benefits. She said her community understands that earning a certain amount causes you to lose rights to certain benefits, but they have no idea what that amount is or how it works in practice. Another Eritrean woman who is a single mother shared a similar story. After three years of working every day in order to have independence for herself and her children, she received a letter saying she should reimburse a huge amount of money that she did not have-all because she did not have the rules properly explained to her. She felt that no one in the service would take responsibility for the problems caused. When she explained to the tax office that because of this she couldn't afford to pay rent or buy food for her children, she was simply told to go to the food bank rather than being offered practical solutions. She became emotional when she said: "Nobody has a voice in a free country. Only those in power at the unemployment services. With one strike of a pen they mess up your lives." She now believes it's better not to work. "You remain dependent, but you stay out of problems."

This sense of the system being broken also comes through powerfully in another person's story about his business failing, leaving him broke and homeless. He felt that the lack of support from the system at the start made his situation worse. This has left them as a "ghost citizen". At first, he was refused support because his case wasn't considered "bad enough", but then when the situation escalated, when he got personally indebted and lost his house, he could not access support anymore because he was not registered in the system. This was because he no longer had a postal address of his own. Asking for benefits while sleeping on the couch with friends would shorten benefits or social assistance from them. 
This former entrepreneur was put under pressure from employment services to accept a job in a factory despite not having any means of travelling to the role. He was told he would not be allowed any benefits if he did not accept the job. He found himself in a Kafkaesque situation.

This case shows how the bureaucratic system becomes authoritarian if instrumental judgement takes over and human relation and values are cut out of decision-making process. The public servant applies the rules based on criteria, measures and ruling defined beforehand. It does not take the context of the person into consideration. This person wants to work but is unable to because of the system and the negative spiral he came into. This sort of paradox is another example of a system that works against itself, causing individuals to be forgotten because they do not fit neatly into one box or another. The system's criteria and indicators seem to produce injustice and enhance the initial problem instead of solving issues that can happen in the life course of any person.

\section{Depersonalization and loss of dignity}

With bureaucratic systems like this in place, it is unsurprising that depersonalization occurs. The stories above show that personal needs are not being listened to. In fact, the anonymous treatment of people as being cases made people feel that they lost their dignity as human beings. The services who were supposed to support them were largely ineffective and even caused more problems. This leads to loss of trust in public services and in political representation and eventually in the democratic system.

The UK pilot sought to enhance personalization in probation services through cocreation. It was shown in many of the stories that a personal approach is necessary and that "one size doesn't fit all". This was shown literally in the following story. A woman in probation was made to do paid work in boots that were too big. In fact, the type of unpaid work she was allocated was usually done by men. She was the only female on the unpaid work site and felt uncomfortable with the "sexism" experienced on the site. She describes her experience and says she "was very scared to be honest... it was really hard". Although she eventually received boots of her own size and she gained more acceptance in the allmale group, the woman was not as positive about her experience at the worksite. Her personal needs as a female - practically and socially - were not met from the start.

Echoing sentiments of this, another woman on probation detailed the importance for probation services to understand how older women on probation feel and to recognize their needs. She wished that probation workers had "treated [her] more like an adult, not like a teenager" and understood issues such as domestic violence that had played a factor in her prosecution. The experience of probation made her feel "belittled" and she felt that it would have been good if her intelligence had been acknowledged. This also shows that, in this case, the probation system is organized in such a way that no room is left for subjective experience and personal capabilities. This harms personal dignity and self-confidence. This understanding is paramount to enabling people to turn their lives around. As one worker explained, "it's about unpacking what has happened in the past to move forward". For them, hearing people's stories should be seen as "privilege" as people trust them with details about their lives. It is through building these relationships of trust and understanding of the people they are supporting that professionals are in position to help people to make positive changes in their lives. 
However, a number of the workers who shared their experiences of working in probation found that, in many instances, the system itself works against this more human and relational approach. They argue that they are confronted with many changes that occur in the service as part of system reforms. Sometimes, staff members feel they are in a constant process of change that is hard to handle. This leaves them uncertain about their professionalism in the way to support people in probation. One worker outlined that the number of cases they need to handle and the computerization of the process has negative consequences on the quality of personal support. He said: "There's far too much computer work". The increase in cases has left him feeling like he "doesn't know whether [they] are coming or going". Furthermore, the computer system in this specific service was often not available due to technical issues. With all the records being stored on it, it made it difficult for workers to do their job when they could not access it. They don't remember the faces of the people they support and, in consequence, they cannot develop a personalized service to those people who depend on it. How, for example, can you build a relationship with someone if you don't know who they are? In this case the computer prevents the worker from developing a genuine interpersonal relationship.

Tech control as self-control

The Italian pilot focuses on reducing childhood obesity. Through storytelling they aimed at gaining a better understanding of how families - parents and children - saw their health and wellbeing. A female child talked about a fitness bracelet she had on at the time of the storytelling. She displayed a high level of awareness about the function of the bracelet and also of her parents' deception in its presentation. She had been told that the bracelet was a present from her grandmother. However, she knew she had it because she was part of "the program" about obesity. She also knew that the bracelet connects to her mother's phone. She revealed the impact that the bracelet had on her behavior. She wore it throughout the night so that the bracelet can continue to count her steps when she gets up in the night and first thing in the morning.

While technology may appear to present easy solutions to monitor health and activity in anti-obesity programs, this story reminds us of its unintended consequences. In fact, through tech we may produce new panopticons (Foucault) in which people exercise self-discipline and gradually lose confidence. The idea of being watched leads to the internalization of other behavior, self-discipline and eventually to self-control. Ultimately it changes behavior but also represents a loss of self-esteem and subjective judgement. E-health monitoring and control impact the feeling of safety and the psychological state of individuals, especially young people, who are depending on the positive encouragement to develop themselves as independent and free adults. Furthermore, it highlights that what is a solution for one person, is not necessarily a solution for someone else and, in fact, could have a negative impact. Following this story, the bracelet was taken away from the child and work was done to reverse any negative consequences of the initial approach.

\section{Othering in public services}

At its worst, a lack of personalization in services can lead to "othering". This is when the service no longer sees the people they are serving as people and they instead become numbers on a spreadsheet. It is at this point that the humanity, compassion and empathy with- 
in a system ceases to exist. In the Swedish pilot, asylum seekers - a group that generally has the least power in society-shared their experiences of public services. One asylum seeker talked about "feeling powerless" with "fate being in the hands of the authorities". He had been told he will have to return to Afghanistan soon. This makes him fear having no family, fear for his life, but he has no say in his situation. Another asylum seeker felt he was "running out of hope" and used his story to plead with the authorities to put themselves in his shoes before deciding on his case.

Awareness of both past trauma and on-going mental anguish that accompanies the uncertainty of an asylum seeker's situation is therefore paramount for services to be able to provide effective and approachable support. Empathy emerges as a key value that individuals seek and have a right to expect from the services supporting them. However, in these instances the consequences of the decisions being made by services on the current lives of people (i.e. negative impact on people's mental health) and future potential consequences (i.e. persecution in their home countries) does not seem to be factored into how asylum seekers are being supported.

Instead, the people within these services make decisions without really connecting to how they impact the people. In fact, the overall austerity policy and defined quota and budget lines are leading. Decision-making about their fate is being anonymized by becoming administrative decisions. In short, the asylum seekers who shared their experiences with us are not being seen. They have become case numbers, not human beings.

When people are "othered", they often feel powerless to affect any kind of change and this leads people to lose hope. One woman who shared her experience as part of the Dutch pilot described feeling "bossed around" by the housing support services. This eventually led to her turning down support from them. This story demonstrates how the ways of interacting with service providers can compound the existing feelings of powerlessness, thus render the services ineffective. They fail to help those that they are supposed to support.

This again is proper to instrumental and purpose-driven ways of organizing public services and calls for re-emphasizing on treatment in line with principles of equality, empathy and humanity. The woman also mentioned that trust in the public service is connected to proper communication between public service staff and the sharing of information about issues at stake, so that the staff has the proper information on what is relevant and important for people that day. Not being listened to or not being seen as a person within institutions ultimately leads to distrust in the institutions that are there to govern and support society.

The stories above show the importance of human-centred approaches and shared ethical values, related to reciprocity, dignity, recognition of personal problems. We will show in the next section how storytelling can contribute to changing the system.

\section{Changing the system: Putting the heart back into public services Value rationality}

The Community Reporter stories gathered do also detail how services are (and can be) delivered in a more human way. In Finland, the pilot explored solutions to youth marginalization - in essence, young people who were not in education or training, and where "drifting" through life. Many of the young people we spoke to as part of the story gath- 
ering process felt like outsiders with no purposes in life and were calling out for someone to talk too. The process of telling their stories through community reporting represented a first step to personal recognition and dignity.

As one young man who is living "a life that sucks" stated: "If I could have someone to talk to and something to do with in my life", that would help. Similarly, one young man who felt isolated due to social exclusion because of his looks and ways of being, suggests that "it would help to have a service where someone connects a few people to meet and get to know each other". Other young people's stories echo this sentiment, with one suggesting having a "cup of coffee" with other young people like them would help. These more social or community forms of support reach people who aren't currently engaged with traditional services.

Making such services feel more informal and less like a service would be key to this type of support. A young man who moved to Finland from Somalia as a teenager said that the family home he was put into when he arrived didn't really feel like a service. Another Somalian man who moved when he was young stated that although he provides immigrants support in accessing services via the official support services, many people would come to his shop for more informal advice and support, instead of contacting the formal services. Support within familiar or community settings would help to engage some of the marginalized (young) people and help them to identify and then address their needs.

In the Spanish pilot, the focus was to support unemployed people-particularly those who were long-term unemployed or at a greater distance from the labor market - to set up their own enterprises. One of the stakeholders involved states that services for unemployed people should seek to "empower" them and be supportive. It is important for such services to understand that "the long-term unemployed people carry an emotional load, and it is important to work on their capabilities and skills".

This understanding has been factored into the pilot and has had several benefits to the people accessing the service. A large part of the support provided by the pilot revolves around the mentoring of the participants. As one person explained: "We felt tremendous support from the mentors and so we have achieved things that without being here would have been impossible. The atmosphere here is very healthy, very calm and colleagues are always willing to help". This way of working creates an enabling environment which makes it possible for their business ideas and themselves as individuals to flourish.

The mentoring is achieved formally by the appointed business mentors and informally by the peer network that the co-working space has created. Both approaches contribute to the supportive environment that the person is referring to. Both have been instrumental in enabling people to development both personally, and professionally, as part of the pilot. A key part of this, as one person acknowledges, is the "real, practical support" that the mentoring provides. It has given her a "grounding" and made the idea of running her own business "real" and "doable". Furthermore, as one person stated, it is not the same to start alone as it is to have some support:

"For me it's been of great support. I have no family who are entrepreneurs so to have those mentors has been of enormous help in how to continue and progress".

In essence, the pilot is successfully reaching out to people who would not usually engage with start-up project and support and offering them opportunities for economic and personal development that they would not have otherwise had access to. Key to this is that the people being supported know that the mentors supporting them care about them (as 
do the other entrepreneurs around them), and this has been key to building relationships of trust.

\section{The strength of togetherness}

This human approach to service delivery centered on relationship building is also evident in the Hungarian pilot that is focused on supporting rural communities to develop household economies. As a member of the Kunszentmárton social cooperative details, co-creation is an important part of the process: "We will prepare it together, we come together, each one of us will have something, and we will do it together." This succinctly summarizes the spirit of many of the stories, which demonstrate examples of various types of community members coming together to become more self-sustaining by reviving household economy traditions.

Exemplifying this is another Kunszentmárton participant who at a cooking event organized by the social cooperative, was responsible for preparing noodles for the first time, says, "I am very excited, because I feel that I am not yet prepared for it. But we have such a community, we are making the program together. I am in it as a member of a social cooperative, and I really like the other members in the cooperative. I can rely on them, and therefore I believe it will be all right." This sense of community support within the areas involved in the pilot is key to enabling people to learn new things and take on new challenges.

One of the key values central in this example are the importance of togetherness, of sharing and the general safety that is provided by the community. People feel encouraged to learn, to ask for help and to experiment with new activities. They feel respected and recognized as individual human beings with their own subjective capabilities, needs and vulnerabilities, which can be shared with others.

\section{Recognition of personal capabilities}

In the Netherlands, a man living with autism had previously a negative experience with the support system around employment and taxation. This had impacted severely on his mental health and financial situation. He describes however that another department of the same municipality had been very supportive. He tells about his work in the archives of the municipality, first in a participation role, which was designed to help people with disabilities to find work, before being given a permanent role.

"Since I returned to the municipality in 2017 [in a participation job] I took giant steps in self-development. The municipality learned a lot from me too. They made many modifications. For instance, they gave me extra space for conversation and to walk outside for a while to 'reset'. I needed this in the beginning because now everything goes so well that I don't need it anymore. [...] The municipality gave me a permanent job at the beginning of 2019. There's a lot of work. I feel very comfortable, and I like it a lot. Now working and living are going well for me". He says that the chance he was given by the municipality was "fantastic": "I belong here. They saw that too." This story shows again that being treated as a person, with personal needs and capacities, and not as a case, makes significant differences for people. The public servants who hired him saw beyond his autism to recognize that he as a person was a great fit for the role and organization and gave him what he needed to thrive. 


\section{Public service delivery is about human values and dignity}

What the instances and ideas outlined in these stories represent is that it is possible to deliver services with humanity based on values such as mutual respect, genuine interest and empathy, based on capabilities of people. To do that, we must ensure that the things that make us human - relationships with others, empathy, emotional intelligence etc. - are at the forefront of service design and delivery. As Davies et al (2020) called for, public services must push back again a culture of "computer says no" and look for nuanced solutions to providing support for the citizens they service. Storytelling - and valuing people's lived experiences - has a role to play in the development of individual and social dignity. Public services should again operate along the lines of value rationality, in which every person feels accepted in his own and unique way and recognized for their personal set of capabilities and skills.

\section{Storytelling as a motor for system change}

Stories of lived experience at the heart of decision making. Within the CoSIE project (and beyond), Community Reporting has been used as a tool for co-creation in different types of public services. What this practice does is put stories-our own personal experiences both as citizens and as professionals - at the centre of discussions and decision-making processes. As has been identified within the CoSIE project, the impact of Community Reporting has mostly been found in the "behaviors and ideologies held by individuals and in the delivery and spaces of services delivered by organizations" (Trowbridge and Willoughby, 2020). As, Trowbridge and Willoughby (2020) suggest:

Whilst there have been some indicators of wider impact... it is unsurprising that systemic impact is an area where little change has occurred. This is because this type of change and impact often takes longer to come to fruition and is usually influenced by interconnected, networked and incremental changes at individual and organizational levels.

In essence, what Community Reporting and the use of storytelling as an approach to system change is asking for is a "paradigmatic shift in terms of how societal and governmental institutions operate" and this is not a quick process (Trowbridge and Willoughby, 2020).

\section{Changing the public service working culture...}

A culture of listening. Nonetheless, this should not imply that storytelling cannot bring about - or at the very least-have a role to play in system change. Just within the CoSIE project we can see the seeds of this in terms of how it has changed the approach of individuals working in services and how they see the value of it. As one of the leaders of the UK pilot explains:

Community Reporting has been a really different way of actually finding out about what staff and service users think about [the service] and what I really like about it is that it is really listening to the voices of people directly rather than putting it through the medium of various councils and panels, which is what [previously] people have been used to. 
A culture of personalization and connection. Based on the stories gathered in the project, a toolkit was co-produced with peer mentors in the probation service and key staff members that foregrounded the use of storytelling to create a working culture of personalization - not just personalization within a service - via the creation of personal connections. As the toolkit identifies, this involves going beyond process and is about really getting to know people. Essentially, this can be achieved by talking to people, hearing their story, and getting to know them.

A culture of holding space. Similarly, in the Dutch pilot, Community Reporting led to the lead Policy Advisor reflecting on and rethinking how the municipality serves its citizens:

It's not rocket science. It's a basic thing that as a civil servant we tend to have an agenda - a well-meaning agenda but an agenda, nonetheless. [Community Reporting] took us away from our agenda and allowed people to make their own.

What this demonstrates is that giving people the space to talk without a specific agenda provides an opportunity to become aware of it and for different thinking to emerge. This process is a sign of (or the seed of) system change - it is abandoning top-down, paternal notions of service delivery and creates space for bottom-up change processes to emerge, perhaps those that are more in-line with asset-based development practices and with notions of inclusion.

\section{Conclusion: Community Reporting as narrative intervention for system change}

Community Reporting in the CoSIE project can be seen as a narrative intervention. All different stakeholders involved in the public service, beneficiaries, public servants, managers and policy makers were interacting together and designing a new story for the public service in question. Community Reporting was both an instrument for common analysis, common sensemaking and designing actions for system change. In this sense, storytelling can be seen as a tool for change, but eventually, it becomes the system change itself (Tesselaar, 2015). By using stories and getting deeper insight in the meaning of individual actions within public services, people will be encouraged to make changes happen. This bottom-up approach asks for professional space within public services. It calls for the ethical reflection upon one's own work and the relationship with others.

What is needed is that all actors involved in the realization of public policy are aware of the role they play and the constant reflection about one's own actions it implies. In fact, instead of talking about accountability of social policy and public services being the working elements in this, it is important to introduce also narrative accountability techniques, based on storytelling, visual accounts, conversations, and films, so that in all phases of policy making and decision-making processes the experience of beneficiaries are at the heart of public service within the public services and public administration. In the next section we will call for a narrative technique within the bureaucratic system of public services. 


\section{The calling of narrative democratic system and responsive governance}

The above experience within the CoSIE project and the impact of stories on innovation of public services is in line with growing awareness that public governance cannot be ruled by an instrumental rationality and cost-benefit ideology that comes with it alone. However, it is not easy to integrate narrative and co-creative approaches into the present system. Public administrations and most organizations work with plans and targets defined beforehand based on prospects. Available resources, time and money constitute a well-defined and predetermined frame. Working with narratives and involving people requires time and space to develop and learn (Sarphatie and Geelhoed, 2020).

The CoSIE project showed that the narrative processes, inherently present in co-creative approaches to innovation, have another starting point. It starts at the heart of the matter, the shared values, instead of the distribution of available resources. Often this does not correspond to planned time, requirements and available resources. It is also important that decision-makers provide for space to integrate open outcomes and unexpected solutions.

These do not always correspond to the budgetary lines and organizational structure of local administrations. Our earlier research on innovative social investment showed, however, development of new initiatives based on shared responsibility, community values, safety and respect for differences, flexibility and reconsideration of predetermined goals. If the targets and goals are not met, this does not mean failure or loss of benefits. It is simply a step forward and a learning process.

However, in line with the work of Pierre Rosanvallon (2008, 2011/2013), these new ways of working are signs of change of democracy itself. He observes a general need for "Narrative Democracy", as he calls it (Rosanvallon, 2015). We need to go back to basics and listen to the stories of those who are not visible, those whose voices are not heard in the political arena and who do not have access to communicational tools (Castells, 2013). Listening becomes a core virtue in public service delivery. Through the sharing of stories, a common understanding of what living together actually means could be achieved. As Rosanvallon underlines, democratic systems are not static structures. In fact, democracy cannot be achieved - it is an ongoing process. It needs to adapt to major, current social transformation and be in tune with our time. We need to strive and fight for democracy and define democratic foundations, based on the stories of all in their own natural and social environments (Rosanvallon, 2011/2013, 2015; Wieviorka, 2020). Therefore our project on co-creation and innovation of public services matters. It strives to lend voice to those who are not heard and is based on listening and adjustment of priorities according to citizen's needs. It offers a learning journey to those who wish to contribute to this fundamental cultural change. ${ }^{3}$

\section{Entanglement of multiple rationalities in public governance systems}

Why it is so complicated is because it asks for a change of organizational culture of the bureaucratic system of public governance and administration. Van der Steen (2011) shows that public governance both on national and local levels operates along different ration-

3 See also CoSIE website https://cosie.turkuamk.fi/results/ It offers not only academic insights but also a practical toolkit. a roadmap to co-creation and a MOOC to make a start with a changing working culture in public services. 
alities, operational at the same time, which may interact and are sometimes in conflict with each other. The quadrant of Van der Steen (see below) shows how instrumental and value-based rationalities are guiding these four major action schemes of the public institutions and public authorities.

Firstly, it is related to the notion of Public Administration, the organization of the democratic system and the maintenance of rights and duties (see bottom left). He would link up to the legal disposition and rule of state. Secondly, public government is related to New Public Management and related to performance and the actual realization of policy in a legitimate, efficient and accountable way and within the available budget, (balance between costs and benefits) (see top left). These two perspectives are primarily ruled by instrumental rationality, based on the legal and managerial instruments. Thirdly, national and local authorities are also focused on Network governance in which extensive cooperation with external stakeholder groups and public/private partnerships are engaged to realize the objectives of governance and policy (see top right). Finally, national and local authorities are aware of societal resilience, to what happens within the active community. This is what Van der Steen calls responsive governance.

Thus, governmental action, be it on national or local levels, have different action frames that interact with each other and that have different instrumental rationality and value rationality as guiding principles. The horizontal axes are indicating the relationship between the public service/ governance and the society, and the vertical axe shows the relationship between results and preconditions. Within public services and their organization, the four fields of the quadrant are operating at the same time.

From results to basic conditions

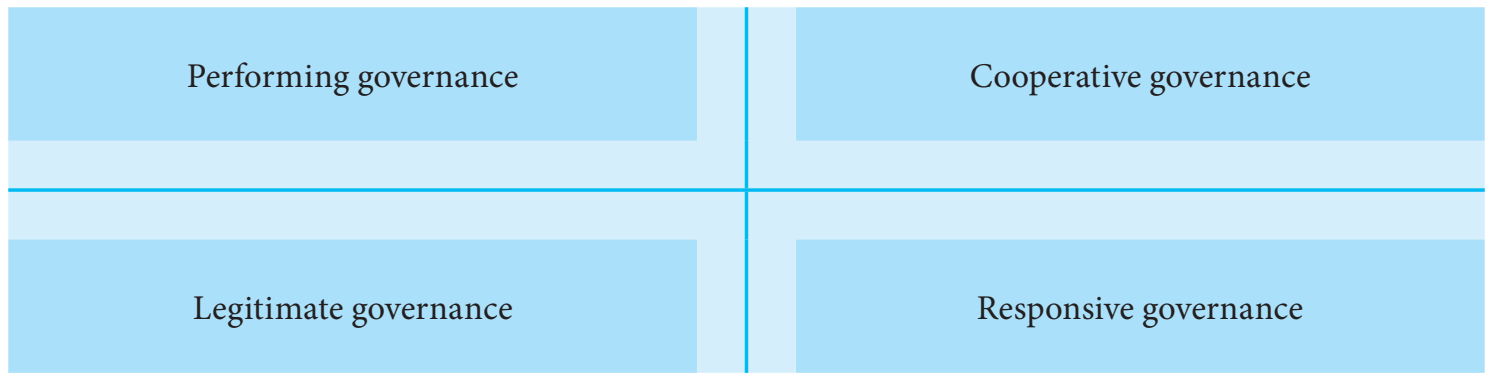

The reality shows that many (governmental) institutions through their public services wish to be a networking and a responsive authority. In practice, however, legitimacy and management are dominant procedures within actual public services, policy making and decision making (Van der Steen, 2015).

Professionals within public organizations need to become aware of these different types of action. Also, in this situation storytelling techniques can help to increase better understanding and awareness of the actual purpose of public institutions. We would therefore also call for narrative approaches within the public administrations and services, and within the decision-making process (policy cycle), so that public and civil servants are able to adopt a reflexive approach to their work and integrate logics of cooperation and resilience within everyday work.

This may help to keep track of the agenda of the community, the persons the service is meant for. Current action research on narrative accountability in the Netherlands (Geel- 
hoed and Sarphatie, 2020; Geelhoed, Sarphatie and Sprinkhuizen, 2020) but also the network for responsive civil servants set up in the Netherlands (Bakker, 2019) shows that there is growing awareness about the urgency for change. From current research results it becomes clear how public services in the Netherlands are counterproductive and even produce injustice (Frederik, 2021; Van Kampen et al. 2020; Knijn, 2021). The actual scandal around fraud regulation in the field of childcare which resulted into unjust accusation of fraud for many families, being obliged by the tax office to reimburse benefits over years of time, which left them heavily indebted, sometimes homeless (Frederik, 2021) or children taken into care. Emphasizing on legimate governance and public management values with regard to citizens who depend upon public services and allowances lead to fundamental injustice, loss of dignity and growing distrust between governance and citizens (Van Kampen et al, 2020).

As we have shown above, Community Reporting can serve as a narrative intervention to provide for new insights on the one hand and open pathways for actual change on the other. In this sense, the "story becomes the change", as Suzanne Tesselaar $(2015,2017)$ states in her many books and interventions. In fact, through storytelling all actors become aware of their professional roles and from this awareness they can build new working relationships based human relations and mutual respect. Thus, civil servants, managers, legislators, organizations and citizens can make a decent working environment together in which public professionals and citizens both feel recognized "in his unique right of being and doing" (Dikkers en De Bell, 2020). Tonkens (2020) calls even for social dignity, which is related to transforming the system in such a way that the system contributes to guarantee a decent life for each person in line, despite all individual and group differences, with their own capabilities and dreams. The real power of storytelling as narrative intervention lies in the mobilization of collective intelligence and imagination, contributing to drafting and crafting our pathway to a common future on this planet.

\section{References}

Castells, Manuel: Communication Power. 2nd edition. Oxford University Press, 2013

Dikkers, Josje en Leendert De Bell: Werken aan waarde. Praktijkgericht onderzoek naar het creëren en duurzaam organiseren van waardig werk. Openbare les. Hogeschool Utrecht, 2020.

Durose, C, Mangan, C, Needham, C, Rees, J, (2013). Transforming local public services through co-production, Birmingham: AHRC Connected Communities / Department for Communities and Local Government / University of Birmingham, p22.

Fermin, Alfons, Sandra Geelhoed en Rob Gründeman: The creation of a socially diverse neighbourhood in Utrecht, the Netherlands. Chapter 9. In: Susan Baines, Andrea Bassi, Judit Csoba and Florian Sipos: Implementing Innovative Social Investment : Strategic Lessons from Europe. Pp. 147-165.

Fermin, Alfons, Sandra Geelhoed en Rob Gründeman: Sociale innovatie als voortdurend proces: 't Groene Sticht en De Volle Grond in Utrecht. In: Dagevos, Hans, Philip Marcel Karré en Guido Walraven: Sociale Innovatie. Van Gorcum, 2018.

Fenger, H., E van der Torre and M. van der Steen: The Responsiveness of Social Policies in Europe. The Neterhlands in comparative perspective. 
Geelhoed, Sandra, Esther Sarphatie and Ard Sprinkhuizen: Op verhaal komen. Bevindingen en observaties in de praktijk: Een handreiking. Utrecht-Amsterdam, 2020.

Geelhoed, Sandra: Verhalen. Hoofdstuk 2. In: Pim van Heijst, Sabrina Keinemans en Nico de Vos: Arts Based Research voor het Sociale Domein. 2019, pp. 37-61.

Geelhoed, Sandra: Après l'Etat social aux Pays-Bas, l'entrepreneur social. In: Pleyers, Geoffrey (et al.) Chapître 11: Subjectivation et désubjectivation. Edition Maison des Sciences de l'Homme, Paris, 2017.

Glasby, J, (2011). Evidence, policy and practice: Critical perspectives in health and social care. Bristol, Policy Press.

Glaser, B. G., \& Strauss, A. L. (1967). The discovery of grounded theory: Strategies for qualitative research. Hawthorne, NY: Aldine de Gruyter.

Jansen, Erik: From Capability approach to Capability-based social policy. In: M.A Yerkes, J. Javornik and A. Kurowska (eds.): Social Policy and the Capability Approach: Concepts, Measurements and Applications. 2019.

Leavy, Patricia: Method meets Art. Third Edition. New York, Guildford Press, 2020.

Montesano Montessori, Nicolina: Why complexity matters. In: Cok Bakker and Nicolina Montesano Montessori (eds.) Complexity in Education. From horror to passion, pp. 261-282, Rotterdam, Sense Publishers, 2016.

Montesano Montessori, Nicolina, N. Farrely and J. Mulderrig (2019): Critical Policy Discourse Analysis. Cheltenham/ Northhampton: Edward Elgar.

Nussbaum, Martha: Creating capabilities: human development approach. Cambridge, Massachusetts, Belknap Press, Harvard University, 2011.

Nussbaum, Martha: Not for profit: why democracy needs humanities, Princeton University Press, 2010.

O Neil, Cathy: Weapons of Math Destruction, Random House, 2016.

Rosanvallon, Pierre: Counter-Democracy. Politics in the age of distrust. Cambridge University Press, New York, 2008.

Rosanvallon, Pierre: La société des égaux. Paris, Le Seuil, 2011 (translation by Arthur Goldhammer: The Society of Equals, Harvard University Press, 2013.

Rosanvallon, Pierre; Le parlement des invisibles. Le Seuil, Raconter la vie, 2015/2020.

Seidl, D. (2007). The dark side of knowledge. Emergence: Complexity and Organization, 9: $1-12$.

Snowden, D and Boone, M. (2007) A leader's framework for decision making. Harvard business review, 85(11), p. 68.

Trowbridge, Hayley and Michael, Willoughby (2020) 'Connecting Voices, Challenging Perspectives and Catalysing Change: Using storytelling as a tool for co-creation in public services across Europe' in CESCI Cross-Border Review Yearbook, James Scott (ed). Central European Service For Cross-Border Initiatives.

Tummers, L., \& Karsten, N. (2012). Reflecting on the Role of Literature in Qualitative Public Administration Research: Learning From Grounded Theory. Administration \& Society, 44(1), 64-86.

Van Heijst, Pim, Nico de Vos and Sabrina Keinemans: Arts-Based Research voor het sociaal domein. le druk, Coutinho, 2019

Kampen, T., M. Sebrechts, T. Knijn \& E. Tonkens (red.): Streng maar onrechtvaardig. De bijstand gewogen. Jaarboek Tijdschrift voor Sociale Vraagstukken, Amsterdam: Van Gennep, 2020. 
Van den Brink, Gabriël, Merlijn van Hulst, Laurens de Graaf, Ton van der Pennen: Best Persons en hun betekenis voor de Nederlandse achterstandswijk. Den Haag: Boom Lemma, 2012.

Van der Steen, Martijn, Jorren Scherpenisse, Maarten Hajer, Olav-Jan van Gerwen en Sonja Kruitwagen: Leren door doen. Overheidsparticipatie in een energieke Samenleving. NSOB, 2014.

Tesselaar, Suzanne en Jacco Roodermond: Narratief evalueren. De gids. Eburon, 2017.

Tesselaar, Suzanne: Storytelling Atlas. Het landschap van verhalen en veranderen. Amsterdam, Boom uitgevers, 2015.

Van Nijendaal, G.A. (2014). Drie decentralisaties in het sociale domein. In: Donders J.H.M. \& de Kam C.A. Jaarboek Overheidsfinanciën 2014, p. 85-100.

Voorberg, W.H. V. Bekkers and L. Tummers: A systematic review of co-creation and co-production. Embarking on the social innovation journey. In: Public management review, volume 17, issue 9, pp. 1333-1357.

Weber, Max: Economy and Society I. Edited by Günther Roth and Claus Wittichm University of California Pressm 1978.

Wieviorka, Michel: Du concept de sujet à celui de "subjectivation/ désubjectivation", FMSH, working paper, nr. 16, 2012.

Wieviorka, Michel: Pour une démocratie de combat. Paris, Le Seuil, 2020. 